\title{
"SUPPORT FOR THE COMPLETION OF THE ARM PROJECT AND DEVELOPMENT OF A FIELD DEMONSTRATION OF THE GWIS MODEL FOR A VIRTUAL ENTERPRISE"
}

Final Report

Subcontract Number 005BZ0019-35

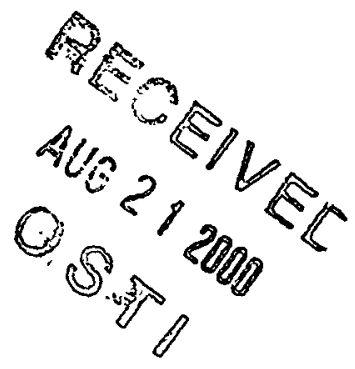

Submitted to

LOS ALAMOS NATIONAL LABORATORY

by

Strategic Technology Resources, L.L.C.

8620 Beverly Hills Ave NE

Albuquerque, NM 87122

Telephone: 505-822-0937

FAX: 505-623-3533

e-mail: martin@strnm.com

Contacts

Mark B. Murphy, Manager and Chief Executive Officer

F. David Martin, Manager and Chief Operating Officer 


\section{DISCLAIMER}

This report was prepared as an account of work sponsored by an agency of the United States Government. Neither the United States Government nor any agency thereof, nor any of their employees, make any warranty, express or implied, or assumes any legal liability or responsibility for the accuracy, completeness, or usefulness of any information, apparatus, product, or process disclosed, or represents that its use would not infringe privately owned rights. Reference herein to any specific commercial product, process, or service by trade name, trademark, manufacturer, or otherwise does not necessarily constitute or imply its endorsement, recommendation, or favoring by the United States Government or any agency thereof. The views and opinions of authors expressed herein do not necessarily state or reflect those of the United States Government or any agency thereof. 


\section{DISCLAIMER}

Portions of this document may be illegible in electronic image products. Images are produced from the best available original document. 


\section{TABLE OF CONTENTS}

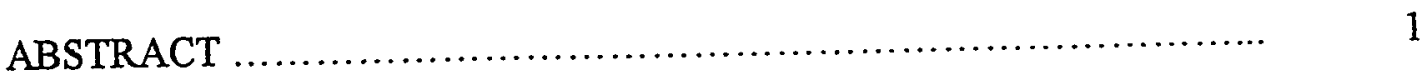

BACKGROUND …............................................

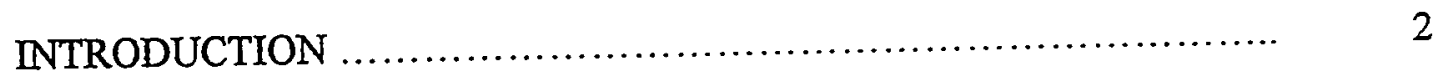

Project Phases and Tasks .................................... 2

Personnel Assigned to the Project ............................... 3

SUMMARY OF PROGRESS .....................................

Managerial and Technical Support ............................ 3

ARM Project Field Studies ................................... 4

Belden \& Blake Corp. Marlboro Field ..................... 4

Flying J Oil \& Gas Brorson Field ......................... 5

Farrar Oil Company West City Unit ....................... 5

Murfin Drilling Company Minneola Property ............... 6

SMACKCO, Ltd. Appleton Field ............................. 7

Ardent Resources Yates County Prospect .................. 8

Espanola Facility .......................................... 9

Support of the GWIS Model for Virtual Enterprises ................ 9

The Virtual Enterprise Model ................................. 10

Selected References and Links to Websites ...................... 17 


\begin{abstract}
Strategic Technology Resources, L.L.C. (STR) provided work for Los Alamos National Laboratory (LANL) in response to Request for Proposal 005BZ0019-35. The objectives of the work in this project were to: (1) support the completion of the Advanced Reservoir Management (ARM) cooperative research and development agreement (CRADA) LA9502037, and (2) support the development of a field demonstration of the LANLdeveloped Global Weapons Information System (GWIS) model for virtual enterprises. The second objective was contingent upon DOE approval of the Advanced Information Management (AIM) CRADA. At the request of the LANL Technical Representative, the project was granted a no-cost extension to November 30, 1999.
\end{abstract}

As part of the project, STR provided managerial support for the ARM CRADA by: (1) assessing the data resources of the participating companies, (2) facilitating the transfer of technical data to LANL, (3) preparing reports, (4) managing communications between the parties to the ARM CRADA, and (5) assisting with the dissemination of information between the parties to technical professional societies and trade associations.

The first phase of the current project was to continue to engage subcontractors to perform tasks in the ARM CRADA for which LANL expertise was lacking. All of the ARM field studies required of the project were completed, and final reports for all of the project studies are appended to this final report.

The second phase of the current project was to support the field demonstration of the GWIS model for virtual enterprises in an oilfield setting. STR developed a hypertext Webpage that describes the concept and implementation of a virtual enterprise for reservoir management in the petroleum industry. Contents of the hypertext document are included in this report on the project.

\title{
BACKGROUND
}

On December 11, 1995, LANL initiated the ARM CRADA with 20 independent oil companies (15 companies actually participated in the CRADA). As part of the DOE's Advanced Computational Technology Initiative (ACTI), the goal of the ARM CRADA was to demonstrate the value of advanced reservoir management technologies and to explore ways to provide sustainable access to modeling technologies, particularly over the Internet. The ARM project leveraged the government's investment in the weapons program and, at the same time, put independent oil and gas producers on a path to more aggressive management of their reserves. The participants in the ARM project were geographically distributed across the U.S., and the reservoir management projects were in fields representing the major oil and gas producing areas in the U.S. Most of the properties in these fields were marginally economic. 
The ARM CRADA introduced advanced simulation and modeling technologies to the participating companies in an attempt to extend the lives of these reservoirs and make the participating companies more competitive in a fiercely competitive world oil market. The driver and delivery vehicle for this effort was the Web-based virtual enterprise model.

STR supported this effort by providing expert consultants to augment the resources at LANL, especially in areas of technology where LANL expertise was lacking and where it would have been cost-prohibitive to hire expert staff at the Laboratory. The current project supports the same general objectives as outlined in the previous subcontract, C73590016-35.

The ARM CRADA focused on the demonstration of the feasibility of supporting weapons design activities and oil $\&$ gas reservoir management as virtual enterprises. If approved, the AIM CRADA would move this effort from the proof-of-concept phase to an actual field demonstration of the virtual enterprise concept. STR supported the implementation of this field trial in the setting of independent oil and gas producers. One of the goals of the AIM CRADA was to develop a robust implementation of the Webbased virtual enterprise for reservoir management. This implementation would address issues like the treatment of distributed data, data security, and secure Web access to advanced reservoir characterization and management software.

\section{INTRODUCTION}

\section{Project Phases and Tasks}

The first phase of the current project was to continue to engage subcontractors to perform tasks that arise in the ARM CRADA for which LANL expertise is lacking. As in work in the prior ARM CRADA, tasks included activities such as seismic data interpretation, multivariate statistical data analysis, geostatistics, and reservoir modeling and simulation. Task 1 of the project involved supporting the ARM CRADA and providing technical support for six ARM subprojects. Task 2 of the project involved maintaining a presence in Espanola, which was initiated originally to support the ARM CRADA. The Espanola setting was located equidistant from the two major oil \& gas producing provinces in New Mexico (San Juan basin and Permian basin).

The second phase of the current project involved the field demonstration of the GWIS model for virtual enterprises in an oilfield setting. Task 3 of the project was to provide technical support and identify needs for a demonstration of the GWIS virtual enterprise model. Task 4 of the project was to identify risk assessment technologies being developed by the AIM CRADA that are appropriate to independent oil and gas producers. Task 5 of the project was to augment the presence in Espanola to include the development and support of a Web server in order to provide information to interested companies about the field trial of the virtual enterprise described in Task 3 , as well as to develop a hypertext tutorial that described the concept and implementation of the virtual enterprise. 


\section{Personnel Assigned to the Project}

F. David Martin and Mark B. Murphy provided overall management and coordination of the project. Part-time students from the Northern New Mexico Community College assisted in the preparation of hypertext documents and maintenance of the STR Website. Experienced subcontractors were employed to assist in the completion of the ARM project studies.

For the Belden \& Blake and Farrar ARM subprojects, the studies were performed by Drs. W. Greg Hazlett and Jerzy Rajtar. Both Drs. Hazlett and Rajtar have significant experience in performing these types of reservoir simulation studies, and have conducted prior studies in Subcontract Number C73590016-35 for Berry Petroleum Co., Midland Resources and initial work performed for Belden \& Blake and Farrar Oil Co. The VIP family of simulators was used for the Belden \& Blake project, and the Merlin simulation software was used for the Farrar project. These simulation programs have the required features necessary for the projects, and the original studies were performed using these software packages.

Dr. Bruce Hart conducted the seismic work for the Flying J, SMACKCO, and Ardent subprojects. Dr. Hart has extensive experience in this type of work, and has performed related work on the SMACKCO and Ardent projects in Subcontract Number C7359001635. As in the past, Dr. Hart used the Landmark software suite for these studies.

For the Murfin subproject, the University of Kansas Energy Research Center and Kansas Geological Survey (KGS) worked together to demonstrate how cost-effective reservoir description, simulation, and management can be integrated to locate additional incremental oil within a mature oil field that is nearing abandonment. The project used high technology tools that are available to an independent operator. Dr. Tim Carr, Section Chief of Petroleum Research at KGS, provided supervision for the Murfin project which was conducted by Mr. Saibal Bhattacharya, a petroleum engineer with experience in reservoir characterization and simulation.

\section{SUMMARY OF PROGRESS}

\section{Managerial and Technical Support}

Because LANL did not have the resources to provide the managerial support and coordination required in the ARM CRADA, STR provided managerial support for the ARM CRADA. This support included coordination of the activities of the companies participating in the ARM CRADA:

- Assess the data resources of the participating companies,

- Facilitate the transfer of technical data to LANL,

- Prepare reports of findings,

- Manage communications between the parties to the ARM CRADA, and, 
- Assist with the dissemination of information between the parties to technical professional societies and trade associations.

\section{ARM Project Field Studies}

Work on all of the field studies was completed, and final reports were written for all of the projects. A summary of each of the field studies is given below, and details of the individual studies can be found in the attached reports on each of the field projects.

\section{Belden \& Blake Corp. Marlboro Field}

The performance of the Marlboro Field in Ohio has been studied with symmetry elements since the early 1990 s. In prior work subcontracted to STR, the principle objective was to help Belden and Blake Corp. decide whether 20-acre infill drilling in the Marlboro Field constitutes a cost-effective redevelopment scheme. This scheme was simulated, and forecasts made with a 3-D reservoir model, with and without cyclic gas injection. A 3-D reservoir model was an updated version of the one created by the GO-NII pilot study during 1994 and updated by LANL during the summer of 1996. Improvements to the model were possible because new well test and production data became available from a four-well field pilot completed in 1997 and an infill well drilled in a similar pattern in the field also during 1997. These data allowed a better definition of the character of the fractured rock, which was a critical piece of information under-represented in the existing reservoir model. In the earlier work, the history match was completed, performance for a number of development options was forecasted, and results were discussed with Belden $\&$ Blake representatives. Results obtained suggested that application of gas cycling to an infill well could have a major positive effect on oil production, and would be a more attractive production strategy than continuing the current strategy, with or without an infill well.

When the current work began there was still a question as to whether a single porosity and permeability model adequately described the field, or whether dual permeability and porosity behavior was required. The specific objectives of this part of the project were to complete the analysis of the Marlboro project, determine if a dual porosity representation of the field justified by the data, and assess what role anisotropies play in the future development of the field. Depending on the outcomes of investigations to answer these questions, forecasts were to be made with the resulting model.

During the current project, the previous model was upgraded to study the behavior of both dual porosity and single porosity systems. The effect of anisotropy was studied and the results were submitted to Belden and Blake personnel for comments. Based on the comments received from the operator, the 3-D reservoir model of the Marlboro Field was updated and improvements were made to the model so that realistic forecasts could be made. The primary goal of this phase of the Marlboro study was to match the existing production history with updated pressure data. A 15-well region selected by Belden \& Blake was simulated. Using this model, 10-year forecasts compared a based case that assumed no operational changes to three cases with different infill well locations. Based 
on oil production rates and cumulative oil production obtained from the simulations, a recommendation was provided regarding the best infill well performance.

\section{Flying J Oil \& Gas Brorson Field}

After initial reservoir characterization work was done by LANL on the Brorson Field located in the Williston Basin in Eastern Montana, a 3-D seismic survey was acquired by Flying J Oil and Gas Co. In the current work on this project, the new seismic data were integrated with wireline logs to develop a geologically-based reservoir model of the Brorson Field. The two principal components of the project included developing realistic depth/structure maps of the units of interest, and mapping the distribution of physical properties in the field by integrating wireline $\log$ and seismic data. Quantitative relationships were sought between log-derived properties and seismic attributes, and then those relationships were used to predict rock properties in interwell areas. The correlations between well and seismic data were developed in the time domain, rather than in the spatial domain as commonly done. Results of this predictive phase were validated by comparing them with depositional and diagenetic models of the field area, as well as with results from seismic modeling of the field geology. The results would then help the operator to identify development-drilling opportunities.

Three-dimensional seismic and log data from Brorson Field area received from Flying $\mathrm{J}$ and were loaded into Landmark Graphics Corporation's "SeisWorks" interpretation package. Several seismic attribute volumes were generated and several horizons were interpreted throughout the seismic volume. Ongoing telephone and e-mail discussions with Flying $J$ personnel were helpful in providing needed background information for project activities. The goal was to provide Flying $J$ with seismic-based maps and other analyses that enabled evaluation of the existing potential of Brorson Field.

A combination of two 3-D seismic attributes was used to predict the thickness of net pay as measured by wireline logs. Some of these areas are associated with faults suggesting that fractures had a major role on porosity development at the Brorson Field. Based on the current work, undrilled areas with thick net pay were predicted within the 3-D seismic area, and these areas represent locations for additional development in the Field.

\section{Farrar Oil Company West City Unit}

A conceptual simulation model was developed previously by STR for the West City Unit located in Illinois. The objectives of the earlier work on this subproject were to assist the operator, Farrar Oil Company, in the analysis of potential redevelopment strategies for optimizing waterflood performance in the Aux Vases sand and to determine possible production enhancement schemes for the West City Unit. A simulation model was developed and run to history match past field performance and forecast future production for several possible operational strategies. In the first phase of the earlier project, all available reservoir and production data were analyzed. A geological model of the reservoir was built using these data. The geological model was a foundation to construct a simulation model of the Aux Vases reservoir. The next phase was to use the simulation 
model to history match the past production. Production data were matched for well groups, and a good match of oil, gas and water rates was achieved. After the historymatching phase was completed, a series of forecasts were performed, and the results were discussed with Farrar Oil Co personnel. During the match, reservoir properties were adjusted to reproduce the actual reservoir behavior as closely as possible. With this phase completed, the simulation model provided an initial tool for production forecasting tasks.

In order to enhance this model and assist Farrar with their development decisions, the objectives of the current work were to modify the conceptual simulation model previously developed, include a more detailed reservoir description, update the model with new production data, add layers at the top to better handle gas movement, and check the history match and revise if necessary. Alternative production scenarios, including ones, which vary the timing of production and injection, were investigated.

In the current project, the model was upgraded to include a more detailed reservoir description. The new model had an additional layer at the top to allow for more realistic gas flow across the top of the reservoir. The past history match was modified and alternative production scenarios were run, and additional cases were run by varying the production and injection schedules. The current work included an updated history match and two oil recovery optimization scenarios for the West City Unit. The primary goal was to use updated production data to rematch the production history for existing groups of wells. After an acceptable match was obtained, two production scenarios and a base case (no change in current operations) were simulated. Details of the development scenarios were designed and incorporated in the forecasting runs. Based on results of the study, a strategy was proposed to generate the highest oil recovery from the Unit.

\section{Murfin Drilling Company Minneola Property}

In an earlier phase of work on the ARM project, 3-D seismic was acquired and interpreted for the Minneola property operated by Murfin Drilling. The objectives of the earlier study were to determine if high-resolution 2-D reflection seismic data could image Atokan sandstones producing in Kansas, and to determine if the high-resolution data could define the Minneola channels better than existing seismic data. The results indicated that, unless another high resolution seismic acquisition method was found to record higher frequencies, identifying thin Morrow sandstones from a pure shale section would be difficult with reflection seismology alone. A complete seismic dataset can be downloaded from the Website at the Kansas Geological Survey.

In the current work, the focus is shifted more toward reservoir characterization and simulation. Specific objectives of the current work were to: consolidate the existing $\log$, production, pressure, and core data, develop an integrated reservoir description, and analyze the Minneola project with reservoir simulation tools. An integrated geologic and engineering reservoir description and characterization, including analysis of existing data, was assembled. Techniques included high-resolution core description, petrophysical analysis of pore system attributes, and analysis of production, pressure, and other engineering data. These data were analyzed with the geophysical data that was gathered 
earlier to see if individual flow units could be determined. All data and analysis were converted to a digital format. A PC-based reservoir simulator, which would be within the reach of an independent producer, was used for the study. Analyses were confined to computer packages that are either freeware or very low-cost.

All of the available data from the Minneola Field (e.g., wireline logs, core, production, pressure and fluid data) was acquired and consolidated into a digital database. PfEFFER (a low-cost spreadsheet log analysis package) was used to determine important parameters and critical cut-offs (e.g., bulk volume water, water saturation, porosity, etc.). Log, core, and fluid data were used to determine parameters to characterize the reservoir. The reservoir data were integrated with the available geophysical data to determine individual flow units and flow barriers within the reservoir. Data and initial maps were loaded into the Online Digital Petroleum Atlas to provide access to all products (e.g., maps, cross sections). These data are available on the Website at the Kansas Geological Survey (http:www.kgs.ukans.edu/DPA/Reports/Minneola). The current characterization results indicate that the reservoir at the Minneola Field consists of three sands as opposed to what was originally considered to be a single layer reservoir. Injection water breakthroughs in the producing wells indicate significant reservoir heterogeneity, and secondary recovery from the waterflood has been very poor. These results suggest that substantial reserves remain to be recovered by the design of an effective recovery strategy.

\section{SMACKCO, Ltd. Appleton Field}

A seismic interpretation project was conducted previously by STR to determine if additional drilling could extend the economic life of the Appleton Field in Alabama. Results suggested that potential undrilled targets remain in and adjacent to the Appleton Field that could be drilled before the field is abandoned. Based on the previous study, a "side-tracking" procedure was performed in an old well to target structure at a bottomhole location approximately $500 \mathrm{ft}$ away. However, the porous zone of the Smackover Formation was encountered $79 \mathrm{ft}$ below the expected location which indicated the need for an improved depth conversion. Reservoir quality of the target structure was somewhat poorer than anticipated, the structure was not as well developed as predicted from the seismic interpretation, and productivity of the well was not economic under oil prices at that point in time.

The objectives of the current work were to review the seismic interpretation previously generated for the Appleton Field and to assist in evaluating the future operations in the Appleton Field. Several different approaches were employed to depth-convert the horizons that were picked in the 3-D seismic volume. The work was done in conjunction with workers in the Computer Science Department of the University of Alabama in order to develop a methodology for using neural networks to derive reservoir physical properties from seismic attributes and well control.

The current work on the Smackco project had two purposes. The first was to understand the differences between the measured and predicted (from 3-D seismic) depth to the top 
of the pay zone in the well that was drilled in the Appleton Field. Work on this part of the project identified several factors that seem to have played a part. Using geostatistical methods and integrating $\log$ and seismic data, new structure maps were prepared that incorporated data from the newly drilled well. The second component of the project was to collaborate with artificial intelligence experts at the University of Alabama in order to try to make a better porosity prediction for the Smackover Formation at the Appleton Field.

A major goal of the current work was to determine the source of error in the earlier depth conversion and to derive more accurate depth conversions using geostatistical techniques. The current work identified three sources of errors that affected the original depth estimate. By correcting for these sources of error and by using geostatistical techniques, the error in depth prediction for the Smackover Formation was reduced from $79 \mathrm{ft}$ to $11 \mathrm{ft}$. The remaining error appeared to be due primarily to variations in the phase of the Smackover porous zone pick that results from unpredictable variations in thickness and physical properties of the major reflectors in the study area.

\section{Ardent Resources Yates County Prospect}

STR contractors previously analyzed 3-D seismic data collected in the Rose Run Play in New York. The objective of the previous study was to evaluate the 3-D seismic data collected in the Rose Run Play in New York. Goals of the earlier study were to use the 3$D$ seismic data volume to investigate prospects of drilling in the Theresa interval and to address the potential of deeper structural trends where only shallow well control exists. Results of this earlier study revealed previously unknown structural details at the level of the Knox Unconformity. The study showed how seismic attributes can be integrated to provide a coherent reservoir model that can be tested by drilling wells, and a new well in the Rose Run Play was successfully drilled. The earlier studies are being used as the basis for the current work by applying geologic concepts from the Rose Run Play to a Yates County prospect in New York.

Based on decisions by Ardent Resources management, work on the Ardent project included reprocessing existing 2-D seismic data, and performing analyses on recently acquired 2-D seismic data. These data are from an exploration target in central New York. Two 2-D seismic lines were provided by Ardent Resources-an initial line that was collected to image shallow targets and a more recent line to image deeper targets. The purpose of this study was to use post-stack processing techniques in an attempt to improve the data quality of the initial line, and to interpret the reprocessed data in conjunction with the newly acquired line to gain insight into the structure in this area. Completion of the post-stack processing identified structural and stratigraphic features in the data that were not visible in the original version of the data. Reservoir faulting appears to have negative implications for successful drilling prospects in the area. 


\section{Espanola Facility}

STR continued to maintain a presence in Espanola that was initiated originally to support the ARM CRADA in a setting equidistant from the two major oil \& gas producing provinces in New Mexico (San Juan and Permian basins). The objective of the Espanola demonstration project was to establish a physical presence in this northern New Mexico community and to demonstrate a virtual enterprise with LANL in the ARM project. STR leased space at the Northern New Mexico Community College (NNMCC), purchased equipment and supplies, and employed personnel to implement the virtual enterprise in Espanola. STR has employed two student workers on a part-time basis and has equipped space at the NNMCC with personal computers, Internet access, and related equipment. The students have received training in Los Alamos and have worked with LANL personnel on various aspects of the ARM project, especially in preparation of hypertext documents and maintenance of a Website.

During the current project, STR continued to lease space at the NNMCC facility in Espanola and employed and trained students at that facility. The NNMCC students maintained the STR Website and created html documents. In early summer 1999, Homesite 4.0 was acquired to allow the students to configure HTML Websites and view the Internet form of the Web document. Homesite 4.0 also allowed the verification of links and the document html tags. WS FTP Pro was also acquired to allow file transfer protocol (FTP) of Website files to the STR server from the Espanola office.

\section{Support of the GWIS Model for Virtual Enterprises}

The second main activity of the current project was to support of a field trial of the GWIS virtual enterprise model. This model was based on Web browser technology and distributed data objects implemented around Oracle 8.0, the POSC-compliant version of the Oracle data base software. Whereas the ARM CRADA focused on the demonstration of the feasibility of supporting weapons design activities and oil \& gas reservoir management as virtual enterprises, the AIM CRADA was to move this effort from the proof-of-concept phase to an actual field demonstration of the virtual enterprise concept. STR was to support the implementation of this field trial in the setting of independent oil and gas producers. One of the goals of the AIM CRADA was to develop a robust implementation of the Web-based virtual enterprise for reservoir management. This implementation was to address issues like the treatment of distributed data, data security, and secure Web access to advanced reservoir characterization and management software. At the request of LANL personal, the field demonstration of the GWIS model was delayed. Therefore, the LANL technical representative requested a modification of the STR contract that extended the period of performance to November 30, 1999.

The main deliverable for this activity was the development of a hypertext tutorial that describes the concept and implementation of a virtual for reservoir management in the petroleum industry. The text for this document is provided below. 


\section{The Virtual Enterprise Model}

Los Alamos National Laboratory (LANL) has provided funding through Strategic Technology Resources, L.L.C. (STR) for the implementation of virtual enterprises in the petroleum industry.

In the current work, STR is providing support the development of a field demonstration of the LANL-developed Global Weapons Information System (GWIS) model for virtual enterprises. This model is based on Web browser technology and distributed data objects implemented around Oracle 8.0.

STR is supporting the implementation of this field trial in the setting of independent oil and gas producers. One of the goals is to develop a robust implementation of the Webbased virtual enterprise for reservoir management. This implementation addresses issues such as the treatment of distributed data, data security, and secure Web access to advanced reservoir characterization and management software.

STR developed a hypertext Webpage tutorial that describes the concept and implementation of a virtual for reservoir management in the petroleum industry. The outline for this document is as follows:

\section{- Introduction}

- Early Experiences with Virtual Enterprises

- Virtual Team for Reservoir Characterization

- $\quad$ The Carpinteria Virtual Team

- $\quad$ Software Sharing over the Internet

- $\quad$ Using the Web to View Reservoir Results

- The Web as a Distributor of Data and Services

- The GWIS Model for Java and Database Tools

- Field Demonstration of the GWIS Model

The content of the tutorial is given in the following paragraphs.

\section{Introduction}

Numerous efforts are underway to make the Internet and World Wide Web more -dynamic and interactive. Examples of these efforts in the petroleum industry include interactive maps of well data (Maps), knowledge visualization software (VxInsight), and Web application server (PetrisConnect). The latter commercial effort is related to the problems and concepts that will be addressed further in this document. 
For decades, the petroleum industry has struggled with problems of disparate data formats, different database systems, in-house developed and purchased applications that do not communicate with each other, and hardware installations that have specialized capabilities but differing operational requirements and application interfaces. Consequently, professionals in the petroleum industry have been hindered in their ability to take advantage of new computing and software technologies in a timely or costeffective manner.

In 1990, the petroleum industry formed an international, not-for-profit organization to address these industry-wide problems. The Petrotechnical Open Software Corporation (POSC) defined a set of specifications to improve sharing of technical information among companies in the petroleum industry.

The nuclear weapons programs in the national laboratories share some of problems outlined above; therefore, a joint effort to investigate solutions to these problems provides leverage to both the weapons program and the petroleum industry. At Los Alamos National Laboratory, the Global Weapons Information System (GWIS) has been exploring the electronic exchange of information and data by using a Web browser, JAVA language (JAVA), Common Object Request Broker Architecture (CORBA), and an object-oriented database system. As part of the GWIS, LANL scientists are developing integrated and Web-based tools for developing interoperable computational and database services for exploration and production (E\&P) applications in the petroleum industry.

In 1997, independent of the work at LANL, the Petroleum Industry set up an alliance for considering similar frameworks. The (OpenSpirit Alliance) is sponsoring the design and development of an E\&P component framework in CORBA. Another industry trend is the Object Data Management Group (ODMG) standard, which is still evolving. These alliances and the status of the LANL-developed GWIS applications are discussed in a recent paper on the subject (PDIM Paper).

LANL is providing support to Strategic Technology Resources, LLC (STR) to support a field demonstration of the GWIS model for virtual enterprises. This document describes the LANL and STR efforts.

\section{Early Experiences with Virtual Enterprises}

Our early attempts and experiences with virtual enterprises in the petroleum industry are described in the literature (SPE Paper) and in proceedings of a 1998 conference (IEA Paper).

In the mid-1990s, Los Alamos National Laboratory (LANL) initiated the Advanced Reservoir Management (ARM) cooperative research and development agreement (CRADA) with some 20 independent oil companies. As part of the DOE's Advanced Computational Technology Initiative, the goal of the ARM CRADA was to demonstrate the value of advanced reservoir management technologies and to explore ways to provide sustainable access to modeling technologies, particularly over the Internet. Thus, the ARM project was a virtual enterprise since inception. The participants (ARM 
Participants) in the ARM project were geographically distributed across the U.S., and the reservoir management projects were in fields representing the major oil and gas producing areas in the U.S.

The (ARM Proiect Website) documents the results of various modeling activities (seismic interpretation, geological and geostatistical modeling, and reservoir simulation) for each of the participating companies. These hypertext Webpages are updated as new results from the projects are obtained so that the participants can use the Internet to check on progress at any time.

\section{Virtual Team for Reservoir Characterization}

All of the participants in the ARM project were linked by E-mail, and some were linked by anonymous ftp sites or other data transfer mechanisms. Virtual co-location, that is, simultaneous sharing of graphical images and software access, was achieved for one of the participants. For most of the other participants, virtual co-location was limited, especially at beginning of the ARM project, because of the unevenness of service available from local Internet service providers and telecommunications companies.

The ARM project provided all of the participating companies with access to experts that were not otherwise available. The experts were scientists and engineers within LANL, as well as experts and consultants from the industry and academia. In each case, the experts were located at considerable distances from the participating companies, so the Internet and Web were used extensively for conducting the projects. We cannot possibly describe all of the ARM projects, but one example will be cited. LANL had acquired data (core, log, and production) from an independent producer in the Midwest for the purpose of performing modeling and simulation work to analyze redevelopment strategies for an existing waterflood project. Because of several nontechnical reasons, it was determined that LANL personnel were not available to complete the proposed work in a timely fashion. Thus, LANL contracted with Strategic Technology Resources (a facilitator) to subcontract with a consultant in Houston to complete the study. The data were transferred electronically to the consultant in Houston who conducted the study. Although LANL personnel had visited with the Midwest producer, neither the facilitator nor the consultant had direct contact with the producer during the project, even though there was extensive interaction and communication, primarily via the Internet

The ARM project has yielded one of the most sophisticated examples of a virtual reservoir management project involving an independent producer reported on to date, the Carpinteria Reservoir Re-Development Project, which is described in the next section.

\section{The Carpinteria Virtual Team}

One of the best examples of how the projects in the ARM virtual enterprise should work is the Carpinteria field re-development project. The (Carpinteria Virtual 
Team) consisted of four major partners: LANL, located in Los Alamos; Pacific Operators Offshore, Inc. (POOI), the operator of the field, located in Santa Barbara, CA; the State Lands Commission of California, located in Long Beach, CA; and the Minerals Management Service of the U.S. Department of the Interior in Camarillo, CA. Because the partners are located at different sites, they made extensive use of the Internet and the virtual enterprise model to pursue the re-development of the Carpinteria offshore field. Since the field has been in production since the late 1960s, many of the producing wells are experiencing high water cuts and sand control problems. This is compounded by the recent abandonment and removal of two offshore platforms to satisfy environmental and aesthetic concerns. As the field straddles the federal-state offshore limit near Santa Barbara, CA, the field must be re-developed with extended-reach wells to tap into unrecovered oil in the state portion of the lease.

An extensive effort to create a unified geological model of the Carpinteria field was accomplished through a collaboration supported by the Web. The partners were able to share access to petrophysical, geological, and engineering databases via the Web, and also shared access to sophisticated geological modeling results as several successively more detailed models of the geology of the field were constructed. The virtual resources used in the project included geologists and engineers employed by the partners, regional geological and petrophysical experts, subcontractors not employed by the partners, University collaborators in Houston, TX, as well as modeling experts from LANL. This project was well beyond the capabilities of any one of the partners in the project.

The (Carpinteria Project Webpage) is an example of the type of data and information from a reservoir management study that can be displayed. Pertinent information on the project includes a description, work statement, and plans for the reservoir management study. Data and results that are available for viewing online include well logs from 215 wells, production history (oil, water, and gas) as well as graphs of water cut and gas-oil ratios for all wells in the field, geological cross-sections, and 3-D geological models of the Carpinteria reservoir.

\section{Software Sharing over the Internet}

Two different producers, Strata Production Company (Strata) and Pacific Operators Offshore, Inc. (POOI) independently submitted proposals on different projects to DOE under the Class III Field Demonstration solicitation. Each company had budgeted for similar geological modeling software. After the two projects were separately approved and the budget negotiations agreed upon with the DOE, the original software vendor had undergone several changes and the pricing structure of the software changed. As a result, Strata and POOI found that the costs of the required software packages were more than originally budgeted. Because both companies were familiar with the concept of Web-based technologies in the ARM project, they began pursuing the idea of a floating license for reservoir modeling software that would allow access by several independent producers on a shared, lower-cost basis. Therefore, POOI and Strata formed a virtual enterprise with a third party, Strategic Technology Resources, LLC (STR). STR completed negotiations with a software vendor, Dynamic Graphics Inc., for a license of their EarthVision® geological modeling package. A usage schedule was agreed upon by 
POOI and Strata for access to the license token, which was floated over the Web. GLOBEtrotter Software's FLEXIm® license software resides on a server operated by an Internet service provider, and serves an EarthVision "token" to these two companies (Software Sharing). Strata, based in Roswell, NM and Pacific Operators Offshore, located in Santa Barbara and in Ventura, CA, take turns using the token on completely unrelated projects. Because neither company needs the license on a full-time basis, this Web-based license sharing arrangement has cut the cost of the software in half, and has enabled each company to access the needed geological modeling software to assist in the characterization of their respective reservoirs, at a considerable savings to each company and to the DOE projects.

\section{Using the Web to View Reservoir Results}

The growth and acceptance of the Web was due, in part, to the ability to display graphics as well as hypertext documents. Conventionally, graphics displayed on the Web have been two-dimensional or two-dimensional versions 3-D graphics, and viewing the graphical representation typically required access to the software that generated the graphic. However, the recent advent of Virtual Reality Modeling Language (VRML) now makes it possible to download three-dimensional objects, which can then be examined and manipulated locally. A user in a virtual company can access a VRML file with an Internet browser (such as Netscape Navigator or Microsoft Internet Explorer) through a plug-in program, for example, a (

Three-dimensional representations from the output of geological modeling packages can be accessed over the Web by directing a VRML browser to the Web address of the VRML file. The browser allows a non-expert user to rotate, zoom, and pan on the object. Using VRML allows a geologist in a remote office to view and evaluate a geological representation that was posted on the Web by an expert modeler. The geologist can then E-mail the expert with any required changes in the model to provide the most realistic representation of the reservoir. (VRML Examples) are available from the ARM project Web document.

\section{The Web as a Distributor of Data and Services}

The Web (or the Internet, which is not confined to the "http" protocol) can act as a data server in a virtual enterprise and as a request broker connecting the end-user, such as a small producer, with data, software, and expert users.

A virtual enterprise permits the distribution of data objects and tasks among remote sites that are connected by the Internet. In this model, the Common Object Request Broker Architecture (CORBA) standard is the foundation of a virtual "data bus" whereby multiple participants in the enterprise may supply or request data. A program called an object request broker (ORB) assures that requests and responses among machines are carried out, and that they are accomplished efficiently and securely. The standard way in which the ORB interacts with various machines is dictated by the CORBA standard, which guarantees that machines on either end of a transaction know what to send and what to receive when a transaction is enacted. This approach simplifies the maintenance of the virtual enterprise over competing technologies such as the "http" protocol familiar 
to Web users. Data objects, e.g. well log traces, are compliant with the Petrotechnical Open Software Corporation's (POSC) Epicenter data model. This approach extends the usability of the POSC standards in the Web environment.

User interfaces are another important issue in the virtual enterprise. Currently, most of the technology interfaces are designed for the expert user; they are obstacles to the uptake of technology by non-expert or occasional users. JAVA applets and applications can be developed to create machine-independent user interfaces that are tailored to the needs and skills of these users. JAVA is an interpreted language that can be used to create documents linking speech, graphics, animations, and text over the Web. The use of Java will confer hardware independence upon the enterprise. With the appropriate interface, a small producer who is not an expert can easily evaluate results from a model that was assembled and validated by an expert user.

Although this model appears to be complex, the enterprise which it can support will be both simple to manage and very powerful. For example, a workflow-directed menu implemented in a Web browser can be installed on a PC in an independent producer's office. A small producer or his agent can manage the virtual enterprise through this browser. Using the browser the independent can post request for services, e.g. log interpretation, geological modeling, reservoir forecasting. The requests could go to something like a bulletin board representing groups of service providers. The respondents who are selected by the independent constitute the virtual team for the project. The independent may also maintain a data server where project data and results will be posted. Security keys can limit access to the data on this server.

A major stumbling block to the implementation of the virtual enterprise has been the management of and access to distributed data. Although the data objects needed to perform a menu-selectable task may exist in diverse formats in geographically remote locations, this should be transparent to the producer. The fact that the data are in neutral or POSC-compliant formats can ensure that the software applications needed to support the enterprise can access it. Moreover, the enterprise can be supported by data protocols which:

- facilitate remote client access to standards-compliant databases, such as Oracle 8.0, the POSC-compliant version of the Oracle database software,

- support a language that operates over the Web (like CORBA),

- allow authorization/authentication at the data object level.

Of course, the use of the Web itself makes the enterprise nearly infinitely extensible. Thus, the virtual reservoir management team supported by the Web can have a lot of depth to allow many potential providers capable of playing roles on the team. 


\section{The GWIS Model for Java and Database Tools}

LANL paper (PDMM Paper) examined object-oriented frameworks in Java and CORBA for developing interoperable computational and database services in Exploration and Production (E\&P) applications in the petroleum industry. They examined some of the issues involved in casting the standard E\&P data model (Epicentre) in CORBA and Java, and considered how the data model and database entities can be directly represented as Java objects for developing integrated and Web enabled applications in E\&P applications.

Experimental tools, based on the Java/CORBA framework and the Epicenter Data Model, have been developed at LANL (LANL Web Tools). The goal of the LANL work is to use the full Java/CORBA framework to develop a software system that will enable "virtual enterprises" focused on reservoir management for independent oil and gas producers. The idea is to make it possible for an independent producer to manage reservoirs in the same way that major producers do with an asset management team that uses best industry practices. The main difference between the LANL approach and that of the majors is that the asset management team is a virtual team. The independent producer and various experts and service providers are linked by Internet and Web applications into a virtual team. These separate organizations and experts would utilize tools based on the common Epicentre data model in Java/CORBA frameworks when exchanging information. Of course, this same model would work for major producers. Many small producers can benefit from the POSC concept of the Shared Earth Model, that is, an earth model that can be used simultaneously by all members of the reservoir management team in a collaborative environment. Examples of this concept are presented in a recent LANL paper (PDIM Paper).

\section{Field Demonstration of the GWIS Model}

STR is providing technical support for a comprehensive field trial of the GWIS virtual enterprise model. STR is supporting the implementation of this field trial in the setting of an independent oil and gas producer. The target partnering company is Pacific Operators Offshore, Inc. (POON). Working with POOI, STR is: (1) identifying the hardware and Internet access needs for the field trial; identifying the goals of the trial, for example, what part of the asset management process the trial will support; (2) identify the external resources need to support the trial, e.g. local consultants, databases, and software; (3) developing a workflow analysis to be implemented with GWIS that supports the goal of the field trial; (4) tracking the success of the trial; (5) providing feedback to LANL; and (6) developing a Web-based report describing the trial. In the goal of developing a robust implementation of the Web-based virtual enterprise for reservoir management, the implementation is addressing issues such as the treatment of distributed data, data security, and secure Web access to advanced reservoir characterization and management software. 


\section{Selected References and Links to Websites}

Ijadi, M. and Kendall, R.P., "JAVA/CORBA Frameworks for Web Applications and Distributed Computing in the Petroleum Industry," paper presented at the "3rd International Conference on Petroleum Data Integration and Management", Houston, TX, April 1999.

Martin, F.D., et al: "Implementation of a Virtual Enterprise for Reservoir Management Applications," paper SPE 38868 presented at the 1997 SPE Annual Technical Conference \& Exhibition, San Antonio, Oct. 5-8.

Martin, F.D., Kendall, R.P., and Whitney, E.M.: "A Virtual Company Concept for Reservoir Management," paper presented at the 1998 International Energy Agency Workshop and Symposium on Enhanced Oil Recovery, Carmel, CA, Oct. 5-7, 1998.

(ARM Project Website): http://www.ees.lanl.gov/EES5/arm

(Carpenteria Project Website): http://www.ees.lanl.gov/EES5/arm/pooi

(VRML Examples): http://www.ees.lanl.gov/EES5/arm/pooi/geo.vrml.html

(PDIM Paper): http://aim.lanl.gov/arm/arm pdim.html

(Maps): http://octane.nmt.edu/maps/MapStart.asp?

(VxInsight): http://www.cs.sandia.gov/projects/VxInsight.html

(PetrisConnect): http://www.petris.com/products/PetrisConnect.html

(POSC): http://www.posc.org

(GWIS): http://www.acl.lanl.gov/GWIS

(JAVA): http://www.java.sun.com

(CORBA): http://www.omg.org

(OpenSpiritAlliance): http://www.prismtechnologies.com/products/openspirit/index.html

(ODMG): http://www.odmg.org

(PDIM Paper): http://aim.lanl.gov/arm/arm_pdim.html

(STR): http://www.strnm.com 